\title{
Leitura e práticas formadoras de leitores: percepções dos bibliotecários do Instituto Federal de Santa Catarina (IFSC) - campi da Região da Grande Florianópolis
}

\author{
Reading and practices training readers: perceptions of libraries of the Federal Institute of \\ Santa Catarina (IFSC) - campi of the Region of the Great Florianópolis (SC).
}

\begin{abstract}
Cristiano Sardá da Conceição
Mestre em Gestão de Unidades de Informação pelo Programa de Pós-Graduação em Gestão da Informação da Universidade do Estado de Santa Catarina - UDESC, Brasil.

E-mail: cristianosard@hotmail.com
\end{abstract}

\author{
Gisela Eggert-Steindel \\ Doutora em Educação pela Universidade de São Paulo - USP, Brasil. \\ Professora do Centro de Ciências Humanas e da Educação da Universidade do Estado de Santa Catarina - \\ UDESC, Brasil. \\ E-mail: f9giza@gmail.com
}

\section{Resumo}

O estudo apresenta um recorte ${ }^{1}$ do conceito de leitura expressado por bibliotecários ${ }^{2}$ do Instituto Federal de Santa Catarina (IFSC), práticas formadoras de leitores ${ }^{3}$ e promoção da leitura nas bibliotecas dessa instituição pública de ensino. Trata-se de uma pesquisa descritiva e qualitativa que utilizou questionário eletrônico enviado a 11 bibliotecários lotados nas bibliotecas do IFSC dos campi da região da Grande Florianópolis, com retorno de aproximadamente $90 \%$ desse universo de bibliotecários. No conceito destes bibliotecários, a leitura é um ato de interpretação e produção de sentidos, pressupondo que a leitura tem uma estreita relação entre informação e conhecimento na clave da leitura, quer de estudo, como a leitura de fruição ou lazer. Desenvolvem práticas de incentivo à leitura com atividades lúdicas sobre obras de literatura de ficção: roda de leitura, leitura e debates e sarau literário, e com divulgação do livro e da leitura: exposição de livros, indicação de obras literárias, trocatroca de livros, estante expositiva e estante permanente de destaque de obras literárias. Práticas estas criadas por estes profissionais da leitura e escrita, informação e conhecimento, no intuito de uma formação continuada de leitores e promoção da leitura reconhecendo a leitura como importante quesito para formação pessoal, acadêmica e profissional.

Palavras-chave: Leitura. Incentivo à leitura. Práticas de Leitura. Formação de leitores. Institutos Federais de Educação, Ciência e Tecnologia.

1 Este artigo traz um recorte de alguns resultados da pesquisa de mestrado intitulada Leitura nas bibliotecas do Instituto Federal de Santa Catarina (IFSC) - Câmpus da Grande Florianópolis: percepções e práticas dos bibliotecários, apresentada no ano 2020 ao Programa de Pós-Graduação em Gestão da Informação (PPGInfo), da Universidade do Estado de Santa Catarina (UDESC).

$2 \mathrm{O}$ universo da pesquisa contempla bibliotecários e bibliotecárias.

3 Entende-se leitores e leitoras.

InCID: R. Ci. Inf. e Doc., Ribeirão Preto, v. 12, n. 2, p. 70-88, set. 2021./fev. 2022. 


\begin{abstract}
The study presents an outline of the concept of reading expressed by librarians from the Federal Institute of Santa Catarina (IFSC), practices that educate readers1 and the promotion of reading in the libraries of this public educational institution. This is a descriptive and qualitative research that used an electronic questionnaire sent to 11 librarians located in the IFSC libraries of campi in the Greater Florianópolis region, with a return of approximately $90 \%$ of this universe of librarians. In the concept of these librarians, reading is an act of interpretation and production of meanings, assuming that reading has a close relationship between information and knowledge in the key of reading, whether for study or for enjoyment or leisure. They develop practices to encourage reading with playful activities on works of fiction literature: reading circle, reading and debates and literary evening and with the dissemination of books and reading: exhibition of books, indication of literary works, book exchange, exhibition and permanent bookshelves of literary works. Practices created by these professionals in reading and writing, information and knowledge in order to provide continuous training for readers and promote reading, recognizing reading as an important aspect for personal, academic and professional training.
\end{abstract}

Keywords: Reading. Reading incentive. Reading Practices. Formation of readers. Federal Institutes of Education, Science and Technology.

\title{
1. Introdução
}

A leitura enquanto um ato é uma ação que prescinde antes de tudo da aquisição da habilidade de ler, decodificar textos, mas é necessário atentar que não se trata só de uma ação mecânica e sim imbuída do contexto social e cultural do leitor. Nas palavras de Martins (2006, p. 23), por muitos séculos, “o aprendizado se baseava em disciplina rígida, por meio de método analítico caracterizado pelo progresso passo a passo: primeiro, decorar o alfabeto; depois, soletrar; por fim, decodificar palavras isoladas, frases, até chegar a textos contínuos". Nesta afirmativa é possível observar que num tempo não muito distante a disciplina foi tomada como condição no processo da aprendizagem da leitura. No entanto, nenhum método de alfabetização por si só garante a formação de leitores efetivos. "Uma vez alfabetizada, a maioria das pessoas se limita à leitura com fins eminentemente pragmáticos, mesmo suspeitando que ler significa inteirar-se do mundo, sendo também uma forma de conquistar autonomia" (MARTINS, 2006, p. 23).

$\mathrm{O}$ ato de ler vai muito além dessa leitura mecânica e ultrapassa a decodificação da palavra escrita. Para Silva, Bernardino e Nogueira (2012, p. 21), "ler é atribuir um sentido ao texto, seja ele apresentado de forma verbal ou não, uma vez que a produção de sentido se constrói na interação entre o autor/texto e leitor, pois a leitura é uma forma de percepção, é a dimensão cognitiva sobre o fazer do outro". Compreendido isso, percebe-se que a leitura é algo muito mais amplo, possibilita a construção de uma sociedade consciente de seus direitos e de seus deveres, permite que se tenha uma visão de mundo e de si mesmo (SOUZA, 2007). 
Neste sentido, a leitura é fundamental, pois, por meio dela adquire-se conhecimento de ordem prática como ampliar-se o vocabulário que pode resultar em melhorar a comunicação e, por sua vez, se posicionar criticamente no seu contexto de mundo.

A leitura é uma prática libertadora, possibilita ascender a um nível mais elevado de vida e construir uma sociedade democrática. Para tanto é necessário investimento em educação e cultura com o estímulo à leitura. Dessa forma, a leitura apresenta-se como um tema muito relevante ao longo da história, e sua discussão torna-se necessária, principalmente atualmente.

O Instituto Federal de Educação, Ciência e Tecnologia de Santa Catarina (IFSC) faz parte da Rede Federal de Educação Profissional, Científica e Tecnológica, vinculada ao Ministério da Educação. Apesar de ter adotado esta denominação recentemente, o IFSC é uma instituição centenária. No início do século XX, por meio do Decreto $n^{\circ} 7566$ de 23 de setembro de 1909, o então presidente da República dos Estados Unidos do Brasil, Nilo Peçanha, cria nas capitais brasileiras as Escolas de Aprendizes Artífices, voltadas ao ensino profissional primário, de caráter público e gratuito. No início do século XXI, com a Lei 11.892 de 29 de dezembro de 2008, foi instituída a atual Rede Federal de Educação Profissional, Científica e Tecnológica (RFEPCT) e criados os Institutos Federais de Educação, Ciência e Tecnologia (IFs). A criação dos IFs possibilitou a convergência dos níveis de ensino nessas instituições e por consequência mudou o perfil e a abrangência de públicos para as suas bibliotecas. São ofertados cursos de ensino técnico integrado ao ensino médio, graduação, pós-graduação, cursos de qualificação, entre outros. Sendo assim, pode-se imaginar como o público dessas bibliotecas é variado. Nas bibliotecas dos IFs, com um público tão diversificado, a temática leitura ganha um importante e novo olhar.

Diante deste cenário, a pesquisa tem como objetivo compreender a leitura no âmbito das bibliotecas do IFSC sob a ótica dos bibliotecários atuantes nos campi da região da Grande Florianópolis (SC). Apresenta um recorte do conceito de leitura expressado por estes profissionais, práticas formadoras de leitores e fomento a leitura nas bibliotecas da instituição. 


\section{As escolhas metodológicas e os procedimentos da pesquisa}

O método de pesquisa delineia a forma como a pesquisa é conduzida, a fim de evitar equívocos, fornecendo subsídios para decisões, com vista a atingir um objetivo. A técnica de pesquisa condiz à parte prática, a capacidade de utilizar os procedimentos e processos formulados no método (LAKATOS; MARCONI, 2010). Neste caso, a finalidade do estudo foi uma pesquisa descritiva de natureza qualitativa. $O$ instrumento de coleta de dados utilizado foi o questionário, com perguntas abertas e fechadas, encaminhado pela ferramenta Google Forms. O delineamento da pesquisa previa a aplicação de um pré-teste que foi realizado para identificar possíveis ruídos de comunicação no decorrer do preenchimento do questionário pelos bibliotecários. O pré-teste foi realizado com uma bibliotecária do IFSC, de um campus fora da região da Grande Florianópolis.

Após alguns ajustes no questionário procedeu-se com a aplicação deste instrumento de coleta de dados, que contemplou o universo de 11 bibliotecários lotados nas bibliotecas dos campi da região da Grande Florianópolis, a saber: Campus Florianópolis (seis bibliotecários); Campus Florianópolis-Continente (dois bibliotecários); Campus Palhoça (uma bibliotecária); e Campus São José (duas bibliotecárias). Obteve-se retorno de dez bibliotecários, o que representa, aproximadamente, $90 \%$ do universo escolhido para a investigação. Informa-se aqui que o Centro de Referência em Formação e Educação a Distância (CERFEAD), localizado no Centro de Florianópolis, possui uma biblioteca e um bibliotecário, mas, não fez parte da pesquisa. Essa não participação do CERFEAD deve-se ao fato de o mesmo não ter as características de campus, isto é, CERFEAD é uma diretoria vinculada à Pró-reitoria de Ensino que atua na implementação e consolidação da Política de Formação do IFSC. Sua biblioteca atende a um público restrito, tendo em vista que a oferta de cursos do CERFEAD é direcionada a servidores da instituição e a outros servidores públicos, tanto da esfera federal quanto estadual e municipal.

Da mesma forma, não fizeram parte da pesquisa as duas bibliotecárias lotadas na reitoria, pois estas não atuam em bibliotecas. Sendo assim, optou-se em não incluí-las ao estudo em tela para não correr o risco de coletar informações com realidades significativamente diferentes das bibliotecas do IFSC selecionadas para a pesquisa.

A proposta da análise de conteúdo de Laurence Bardin, foi o recurso metodológico que se lançou mão para compreender os dados empíricos interpretados à luz de um arcabouço 
teórico. A análise de conteúdo de acordo com Bardin (2009, p. 44) é:

Um conjunto de técnicas de análise das comunicações visando obter por procedimentos sistemáticos e objetivos de descrição do conteúdo das mensagens indicadores (quantitativos ou não) que permitam a inferência de conhecimentos relativos às condições de produção/recepção (variáveis inferidas) destas mensagens.

A autora supracitada divide a análise de conteúdo em três etapas: pré-análise, exploração do material e tratamento dos resultados.

\begin{abstract}
A pré-análise é a fase de organização, de forma a "sistematizar as ideias iniciais, de maneira a conduzir a um esquema preciso do desenvolvimento das operações sucessivas, num plano de análise. A segunda etapa é a exploração do material, uma fase longa e fastidiosa, consiste essencialmente em operações de codificação, decomposição ou enumeração, em função de regras previamente formuladas. A terceira etapa contempla o tratamento dos resultados obtidos e interpretação. Nesta fase, "tendo à sua disposição resultados significativos e fiéis, o analista pode então propor inferências e adiantar interpretações a propósito dos objetivos previstos, ou que digam respeito a outras descobertas inesperadas (BARDIN, 2009, p. 121).
\end{abstract}

Como primeiro passo, foram elencadas todas as respostas na íntegra, com o objetivo de compreender o contexto das respostas. Na sequência foram selecionados os recortes (unidades de registro) para proceder com a escolha das categorias. Com a categorização foi possível mensurar a frequência das categorias mencionadas pelos bibliotecários respondentes.

\title{
3. Os bibliotecários desse universo de pesquisa
}

A primeira parte do questionário aplicado versou sobre o perfil desses bibliotecários caracterizando, a partir de suas declarações, o gênero e a idade, a formação e a qualificação profissional ao longo de sua carreira. A predominância é feminina, característica que ainda permanece neste campo profissional, isto é, 60\% (seis bibliotecárias) e $40 \%$ (quatro bibliotecários), esses todos com idades entre 31 e 50 anos.

A obtenção do diploma de bacharel no campo da Biblioteconomia, segundo as informações obtidas, foi em universidades do Sul do Brasil, sendo 60\% na Universidade do Estado de Santa Catarina (UDESC), 30\% na Universidade Federal de Santa Catarina (UFSC) e 10\% com graduação na Universidade Federal de Rio Grande (FURG). Em relação ao ano da graduação em Biblioteconomia, dois bibliotecários têm graduação realizada na década de 1990; seis bibliotecários concluíram seus estudos na década de 2000; e dois bibliotecários concluíram o curso na década de 2010. Podemos inferir que $80 \%$ do universo pesquisado concluíram a sua graduação já no século XXI. 
No quesito se estes bibliotecários obtiveram outra graduação, nove deles afirmaram que não, e apenas um declarou ter outra formação, graduação no campo do Direito. Já, sobre a qualificação profissional continuada, cinco respondentes informaram a titulação de especialista, enquanto os outros cinco são mestres. Nenhum dos bibliotecários possui o título de doutor. Por outro lado, nenhum dos respondentes tem apenas o nível superior, $100 \%$ dos bibliotecários são pós-graduados.

Constata-se que $70 \%$ dos bibliotecários pesquisados tem 10 anos ou mais de tempo de serviço nessa instituição, ingressaram na instituição até o ano 2010. Os três últimos bibliotecários (30\%) a entrar no IFSC ingressaram no ano 2013 (dois bibliotecários) e no ano 2012 (um bibliotecário), ou seja, têm pelo menos sete anos de experiência no cargo de bibliotecário atuando nas bibliotecas do IFSC. Isso revela que os campi da região da Grande Florianópolis têm uma equipe de bibliotecários que conhece bem a instituição.

Com o intuito de identificar as atividades que mais se ocupam nas bibliotecas dos seus campi e compará-las com as atividades de sua preferência foi questionado qual a atividade que realizam com mais frequência e qual a atividade que mais gostam de realizar.

Ao analisar as respostas das duas questões, nota-se que as duas atividades mais citadas são as mesmas: processamento técnico e atendimento ao usuário. No entanto, para entender melhor e saber se os bibliotecários estão atuando com as atividades de sua preferência foi elaborado o quadro 1. Visando manter o anonimato da pesquisa, os dez respondentes são representados pelos códigos B.1 a B.10.

Quadro 1 - Comparativo entre as atividades

\begin{tabular}{|c|c|c|}
\hline Respondente & Atividade que tem preferência & Atividade que realiza com mais frequência \\
\hline B.7 & Processamento técnico & Processamento técnico \\
\hline B.9 & Processamento técnico & Processamento técnico \\
B.10 & Processamento técnico & Processamento técnico \\
\hline B. 4 & Processamento técnico & Serviço de referência \\
\hline B.2 & Atendimento ao usuário & Processamento técnico \\
\hline B.3 & Atendimento ao usuário & Processamento técnico \\
\hline B.5 & Atendimento ao usuário & Processamento técnico \\
\hline B.6 & Ações culturais & Ações culturais \\
\hline B.1 & Gestão & Atendimento ao usuário \\
\hline B. 8 & Gerenciamento sala de computadores & Atendimento ao usuário \\
\hline
\end{tabular}


No quadro 1, estão em destaque os $40 \%$ dos bibliotecários que realizam com mais frequência atividade de sua preferência. Do universo pesquisado, 60\% informaram atuar com mais frequência em atividade que não são de sua preferência. Dos dados ainda se pode depreender que $10 \%$ afirmaram ter preferência em desenvolver ou trabalhar com ações culturais, o que nos permite inferir que trabalhar com a leitura não é uma atividade de prevalência entre os bibliotecários deste universo.

\section{Compreensão sobre leitura}

Martins (2006) acredita que se nos perguntarmos o que é, o que significa a leitura para nós mesmos, certamente cada um chegará a uma resposta diferenciada. Isso porque se trata, antes de mais nada, de uma experiência individual, cujos limites não estão demarcados pelo tempo em que nos detemos nos sinais ou pelo espaço ocupado por eles. Por essa razão, essa pesquisa não tem a pretensão de testar os conhecimentos dos bibliotecários, tampouco fazerlhes perguntas para saber quem sabe mais ou menos sobre o tema. Mas, estimular o debate e promover reflexões.

Para que pudessem ficar à vontade e discorrer sobre o tema de forma espontânea, optou-se em fazer uma pergunta bem genérica: $O$ que é leitura para você? Dessa forma, os respondentes puderam fazer uso da sua imaginação e, com as suas próprias palavras, expor o que pensam sobre o tema sem que ficassem "presos" a respostas acadêmicas.

Para selecionar os recortes (unidades de registro) das falas e formar as categorias, foi preciso analisar as respostas na íntegra. Com isso, obteve-se 28 respostas. Estas últimas foram padronizadas formando 14 categorias, conforme descritas no quadro 2. 
Quadro 2 - Frequência das categorias

\begin{tabular}{|l|c|c|}
\hline Categorias & Frequência & Percentual \\
\hline Conhecimento & 6 & $21,4 \%$ \\
\hline Entretenimento & 4 & $14,3 \%$ \\
\hline Imaginação & 3 & $10,7 \%$ \\
Informação & 3 & $10,7 \%$ \\
Trabalho & 2 & $7,1 \%$ \\
Vida & 2 & $7,1 \%$ \\
\hline Concentração & 1 & $3,6 \%$ \\
Cultura & 1 & $3,6 \%$ \\
Decodificação & 1 & $3,6 \%$ \\
Formação & 1 & $3,6 \%$ \\
Interpretação & 1 & $3,6 \%$ \\
Liberdade & 1 & $3,6 \%$ \\
Sentido & 1 & $3,6 \%$ \\
Transformação & 1 & $3,6 \%$ \\
Total & $\mathbf{2 8}$ & $\mathbf{1 0 0 \%}$ \\
\hline
\end{tabular}

Fonte: Dados da pesquisa (2020)

Ao observar o quadro acima, percebe-se que a categoria mais citada foi conhecimento $(21,4 \%)$, esta pode ser compreendida no campo da leitura de estudos seguindo-se a leitura de entretenimento ou fruição $(14,3 \%)$. Na sequência apareceram as categorias imaginação $(10,7 \%)$; informação $(10,7 \%)$; trabalho $(7,1 \%)$; e vida $(7,1 \%)$. Oito categorias foram citadas com o mesmo percentual $(3,6 \%)$, a saber: concentração; cultura; decodificação; formação; interpretação; liberdade; sentido; e transformação.

Os termos conhecimento e informação muitas vezes são confundidos. Para compreender a diferença entre um e outro torna-se importante entender a tríade dado, informação e conhecimento, pois os três estão relacionados. Pode-se afirmar que dados são elementos primários, apresentados na sua forma bruta, que podem servir como insumo para a informação. Informação são dados trabalhados, geralmente registrados em suporte físico ou digital e servem de matéria-prima para se produzir conhecimento. Conhecimento é a informação contextualizada, de maneira que, ao se fazer o uso desta última, a mesma poderá se transformar em conhecimento. O conhecimento poderá ser utilizado para a tomada de decisões. A leitura, por sua vez, tem uma relação muito forte com a informação e o conhecimento. Com base em algumas respostas obtidas pelos bibliotecários foi possível tecer alguns comentários. 
"[A leitura] É a ação em que o indivíduo se apropria de determinada informação ou conjunto de informações registrada em um dado suporte" (B.4).

Neste sentido, Almeida Júnior (2007), defende que a leitura está no cerne da apropriação da informação. Para este autor, a informação não existe antecipadamente. Por ser intangível, a informação precisa do documento para ser veiculada e apropriada, e só se concretiza com o processo da mediação da informação. De acordo Barreto (2015), a informação assimilada modifica o estoque mental de saber do indivíduo e traz benefícios para o seu desenvolvimento pessoal e da sociedade em que ele vive. Portanto, pode-se concluir que é por meio da leitura que acontece essa apropriação da informação e, consequentemente, a aquisição de conhecimento por parte do leitor.

"A leitura pode ocorrer por meio de um ou mais sentidos: visão, audição ou tato" (B.4).

Almeida Júnior (2007) concorda com essa afirmação quando destaca que a leitura pode se utilizar de qualquer tipo de documento e a informação também pode ser veiculada uma única vez, como é o caso do teatro, de uma apresentação musical, um recital, uma leitura dramática, um sarau etc. Assim, além da apropriação da informação e geração do conhecimento, a leitura, que pode ser feita de várias formas, também proporciona entretenimento.

"Leitura é interpretar textos; pode ser para entretenimento, estudo ou informação" (B.1).

A leitura realmente envolve interpretação e atribuição de sentido, independente da forma como a informação se apresenta, pois, conforme aponta Silva (2009, p. 67), "não se leem apenas os livros, lê-se o mundo, que se revela ao leitor atento sob múltiplas linguagens: lê-se um filme, um texto ou uma imagem publicitária, um rosto, um gesto, um tom de voz." Em outras palavras, tudo o que está ao nosso redor pode ser lido, na medida que se apresente com a possibilidade de ser interpretado. Caldin (2003) destaca que a leitura tem uma dimensão social, pois permite diferentes interpretações, encaminha a reflexões e pode enriquecer um debate. A autora considera que a diversidade de interpretação por si só já é uma forma de democracia, na medida que permite que o texto literário, por exemplo, seja o lugar da discordância de múltiplas vozes e leituras.

"[A leitura] É silenciar os pensamentos e mergulhar no imaginário desconhecido" (B.2).

Nesse caso, o respondente enfatiza a concentração e momento íntimo que a leitura pode proporcionar. Almeida Júnior (2007) reflete que a leitura nos leva a uma viagem pelo 
imaginário, permite caminhar pelos espaços do sonho, possibilita a vivência momentânea dos desejos, das vontades e dos anseios reprimidos ou impossíveis de serem concretamente realizados.

Petit (2013, p. 49) aponta que "a leitura de obras literárias, nos introduz também em um tempo próprio, distante da agitação cotidiana, em que a fantasia tem livre curso e permite imaginar outras possibilidades". E conclui que "sem sonho, sem fantasia, não há pensamento nem criatividade." Nesse sentido, outro respondente acredita que leitura

\section{"é viajar e conhecer outros mundos; é aprender novas informações; é transformar nossa realidade" (B.6).}

A resposta é bastante significativa, pois, contempla a imaginação, que pode-se atribuir à leitura literária; o conhecimento, adquirido por meio da apropriação de "novas informações"; e a transformação, que pode ocorrer na medida em que o leitor faz uso do conhecimento adquirido com a leitura e modifica a sua realidade à partir da sua atuação sobre ela.

Para além dessas concepções, outro respondente afirma:

"leitura é vida, conhecimento e liberdade” (B.8).

Ao relacionar a leitura à palavra liberdade, pode-se imaginar a leitura como uma prática libertadora. Foi neste sentido que Paulo Freire atuou em diversos países, inclusive durante os anos em que esteve exilado. Em parceria com os governos locais Freire coordenou trabalhos de alfabetização que tinha como princípio uma educação libertadora, na qual os habitantes não apenas aprendiam a ler e a escrever, mas, a pensar por conta própria e a fazer parte da reconstrução do país com participação crítica e democrática. "Quanto mais conscientemente faça a sua História, tanto mais o povo perceberá, com lucidez, as dificuldades que tem a enfrentar, no domínio econômico, social e cultural, no processo permanente da sua libertação" (FREIRE, 2003, p. 41).

Paulo Freire atuava com uma proposta de educação popular, na qual a alfabetização tinha como um dos objetivos educar para a liberdade. Essa educação libertadora encaminhava o leitor para uma leitura crítica. Freire (2003) partia da premissa que o indivíduo aprende a ler o mundo antes mesmo de aprender o alfabeto.

A leitura do mundo precede a leitura da palavra, daí que a posterior leitura desta não possa prescindir da continuidade da leitura daquele. Linguagem e realidade se prendem dinamicamente. A compreensão do texto a ser alcançada por sua leitura crítica implica a percepção das relações entre o texto e o contexto (FREIRE, 2003, p. $11)$. 
As pessoas constroem sentidos ao longo da vida, não somente pela leitura aprendida na escola, mas pela leitura de mundo, e essa leitura de mundo somada à leitura da palavra é leitura que transforma.

Almeida Júnior (2007, p. 33) nos lembra que "inúmeras são as definições e conceitos articulados e elaborados pelo homem para a leitura, quer pendendo para um caráter mais político, mais social, quer para um caráter mais instrumental ou mais técnico". E neste sentido as contribuições dos bibliotecários por meio dessas respostas foram fundamentais para compreender melhor a sua percepção sobre este tema tão importante para as bibliotecas: leitura.

Dando continuidade à seção acerca da compreensão sobre leitura, com o intuito de entender melhor como se desenvolveu o hábito da leitura nos bibliotecários, pensou-se em levá-los de volta ao passado para recordar como era a leitura na infância. Então se perguntou: Com que frequência você lia na infância? Ao responder sobre a frequência de leitura na infância, $70 \%$ dos respondentes afirmaram que liam frequentemente; $20 \%$ afirmaram que liam sempre; apenas $10 \%$ disseram que liam raramente. Nenhum dos bibliotecários respondeu que nunca lia na infância. $\mathrm{O}$ gosto e hábito da leitura na infância pode ser um fator determinante para formar um bom leitor. Um ambiente familiar que proporciona o contato com os livros desde cedo estimula curiosidade da criança. Mas, Petit (2011) alerta que não devemos ser ingênuos a ponto de pensar que a leitura e a literatura vão resolver todos os problemas sociais do mundo. No entanto ela acredita que a leitura serve como um apoio, uma forma de colocar a cabeça para pensar, de modo que o leitor se autoquestione, tenha desejos e busque outras coisas. Em outras palavras, a autora crê que apesar de a leitura em si não salvar o mundo, pode amenizar as dores de pessoas que estão em situações delicadas. Essa autora argumenta, ainda, que os discursos de glorificação da leitura espantam os jovens.

Seja pai ou professor, quem diz que uma criança tem que ler (ou pior: que tem que gostar de ler!) faz da leitura um fardo ao qual ela precisa se submeter para satisfazer os adultos. O impasse está garantido se quem diz que "ler é um prazer" não tem nenhum gosto pela leitura: a criança vai sentir que a pessoa não está sendo sincera (PETIT, 2011, p. 4).

Daí a importância dos pais lerem para as crianças desde cedo, antes mesmo da alfabetização. Dentro de casa os pais são os exemplos. Se a criança vê o pai ou a mãe praticando a leitura, quase certo que a criança despertará a curiosidade e provavelmente terá interesse em experimentar a leitura. Adquire-se o hábito da leitura mais naturalmente quando 
desenvolvido de forma gradual, desde cedo. Assim, a criança tem grandes chances de se tornar um jovem e um adulto leitor, consciente do seu papel na sociedade.

Com a intenção de conhecer os tipos de leitura literária preferida pelos bibliotecários, fez-se a seguinte pergunta: Qual a sua preferência de leitura literária? Neste quesito, 30\% afirmaram que preferem a leitura de romance; $20 \%$ preferem a leitura de conto; $20 \%$ a leitura de autoajuda; $20 \%$ a leitura de ficção científica; enquanto $10 \%$ afirmaram que prefere a leitura de ciências sociais. A leitura literária proporciona momentos de devaneio para o leitor. Ao realizar a leitura de um romance ou de um conto, o leitor pode adentrar em um mundo particular, diferente da sua realidade, e experimentar novas sensações. Silva (2009, p. 131) lembra que "sendo alguém diferente de si mesmo durante o tempo da leitura, ele [leitor] se torna capaz de abarcar melhor a pluralidade, a diversidade que preside as relações sociais." A literatura não pode ficar de fora do processo de formação do indivíduo. A literatura estimula o leitor e o encaminha para o efetivo exercício da cidadania, de maneira livre e mais consciente.

No intuito de conhecer como esse bibliotecário se percebe leitor, foi perguntado: Você se considera um bibliotecário leitor? Nesta questão, $60 \%$ bibliotecários declaram-se bibliotecários leitores, enquanto $40 \%$ bibliotecários afirmam não se considerarem como tal.

É necessário destacar que a importância da leitura não se mede apenas pelo número de obras lidas ou emprestadas. Para Petit (2009, p. 77),

é possível ser um leitor pouco ativo em termos estatísticos, e ter conhecido a
experiência da leitura em toda a sua extensão - quero dizer, ter tido acesso a
diferentes registros, e ter encontrado, particularmente, em um texto escrito, palavras
que o transformaram, algumas vezes muito tempo depois de tê-las lido.

Pode-se dizer que um bom leitor tem o hábito da leitura e a faz regularmente. No entanto, não é somente a quantidade de livros lidos que vai determinar a qualidade e o aproveitamento dessas leituras. 


\section{Práticas de incentivo à leitura nas bibliotecas do IFSC segundo os bibliotecários}

Quando questionados se já participaram de cursos relacionados à área de leitura e/ou formação de leitores, $40 \%$ dos bibliotecários afirmaram já terem participado, 50\% responderam não, e 10\% responderam não lembro. No entanto, ao perguntar se desenvolvem ou já desenvolveram alguma prática de leitura na biblioteca do seu ou de outro campus, 70\% responderam que sim. Esse é um dado interessante, pois, mesmo não tendo realizado capacitação específica na área da leitura, a maioria dos bibliotecários participou, na prática, de ações relacionadas ao tema. $\mathrm{O}$ quadro 3 elenca as práticas de incentivo à leitura mencionadas pelos bibliotecários.

Quadro 3 - Práticas de incentivo à leitura realizadas pelos bibliotecários

\begin{tabular}{|l|}
\hline \multicolumn{1}{|c|}{ Práticas de incentivo à leitura } \\
\hline WC Leitura \\
\hline Arte e Cultura na Biblioteca: Releitura de obras \\
\hline Young Activity \\
\hline Livros, cinema, leitura e debates \\
\hline Roda de leitura \\
\hline Sarau Literário \\
\hline Exposição de livros \\
\hline Indicação de obras literárias \\
\hline Troca-troca de livros \\
\hline Varal Literário \\
\hline Estante expositiva \\
\hline Estante permanente de destaque de obras literárias \\
\hline Fonte: Dados da pesquisa (2020) \\
\hline
\end{tabular}

É importante ressaltar que das 12 práticas mencionadas pelos bibliotecários, 50\% foram realizadas em campi fora da região da Grande Florianópolis. Isso aconteceu porque alguns bibliotecários participantes da pesquisa já foram lotados em outros campi e foram removidos. Acredita-se que estes bibliotecários podem fazer uso da sua experiência e contribuir com novas práticas de incentivo à leitura nas bibliotecas dos campi em que estão lotados atualmente.

Foram identificadas práticas de incentivo à leitura, com atividades lúdicas sobre obras de literatura de ficção, e práticas com divulgação do livro e da leitura. Algumas delas merecem destaque, como o Sarau Literário, narrado da seguinte forma: 
Organizamos o Sarau Literário com os alunos da turma da professora de português do campus para a declamação de poesia ou algum texto literário para apresentar. Fizemos um varal literário com diversos contos e poesias para quem quisesse escolher na hora um e declamar. As servidoras da Biblioteca, faziam a seleção e impressão dos textos escolhidos. Posteriormente mudamos para Sarau Cultural, pois além de declamação de poemas e leituras, incluímos música, dança, teatro (B.2).

Petit (2010), ao examinar materiais sobre experiências de mediadores em contextos de crise, ficou impressionada com o fato de que pessoas de diversas formações "redescobriam, em diferentes pontos do mundo, que a leitura de um conto, de uma lenda, de um poema, de um livro ilustrado podia permitir falar as coisas de outra maneira, a uma certa distância" (PETIT, 2010, p. 204). É o que a autora chama de força da metáfora. Quando se utiliza livros com a intenção de que o leitor chegue a conclusões predeterminadas pelo autor ou pelo mediador, impede-se que o leitor se refugie em outros mundos, que viaje pelos pensamentos. A metáfora muitas vezes contida nos contos e nas poesias permite a superação de um trauma e possibilita a reconstrução de sentido por parte do leitor, justamente por não tocar diretamente na "ferida". Petit (2010, p. 206) destaca que "uma metáfora permite dar sentido a uma tragédia e evita, ao mesmo tempo, que ela seja evocada diretamente; permite também transformar experiências dolorosas, elaborar a perda, assim como restabelecer vínculos sociais." Ao incluir a música, a dança e o teatro, o Sarau Literário proporciona um momento de entretenimento no qual os participantes terão a oportunidade de produzir cultura e não apenas consumi-la.

Neste sentido, outra prática desenvolvida que envolve literatura é a Arte e Cultura na

\section{Biblioteca: Releitura de obras.}

Foram realizadas releituras dos livros "A Revolução dos Bichos” de George Orwel e a leitura em cena de "Othelito" com intuito de que os estudantes percebessem a importância da literatura como ferramenta para solução de problemas cotidianos (B.1).

Esse tipo de linguagem literária, como a citada $A$ revolução dos bichos, de George Orwel, permite que o leitor faça uma análise crítica da realidade ao associar a ficção à vida real. Muitas vezes acontece a identificação por parte do leitor com algum personagem e, de acordo com Silva (2009, p. 72), “o exercício que o leitor é levado constantemente a fazer de vivenciar emoções alheias, de compartilhar angústias e dilemas com os personagens das narrativas é um exercício de cidadania." Para a autora, na medida que o leitor consegue sair do seu círculo pessoal e pensar além da sua realidade torna-se mais apto a criticar, a julgar, a exigir, a definir-se como verdadeiro cidadão. Petit (2010) destaca que a literatura, a cultura e a arte não são uma futilidade, mas algo de que nos apropriamos e que deveria estar à disposição 
de todos, desde a mais jovem idade. A leitura de obras com teor conotativo mobiliza o leitor e o encaminha a uma atividade de reflexão, e isso pode contribuir e muito com a democratização da cultura nas bibliotecas do IFSC.

A composição do acervo foi lembrada pelos respondentes como um fator crucial para o desenvolvimento de práticas de incentivo à leitura nas bibliotecas do IFSC. De acordo com os bibliotecários, um acervo limitado prejudica diretamente a realização dessas atividades, pois, segundo eles, os estudantes geralmente estão em busca de novidades em termos de literatura.

Das práticas de incentivo à leitura realizadas pelos bibliotecários, algumas foram desenvolvidas neste sentido, como a Exposição de Livros.

Compra de livros de literatura e divulgação destas obras por meio de exposições e fanpage. Consistia em utilizar o dinheiro recebido de multas para adquirir obras atuais e proporcionar o acesso a essas obras (B.3).

Demonstrando preocupação com a divulgação do acervo, um dos bibliotecários afirma ser importante investir na aproximação dos leitores com a biblioteca e os livros, de modo que os leitores se sintam atraídos.

Muitas vezes os livros são adquiridos mas não são divulgados e acabam esquecidos nas estantes. É preciso que o bibliotecário conheça seu acervo e faça sua divulgação constante, não apenas quando são novos (B.1).

E neste sentido as ações de incentivo à leitura têm grande contribuição, pois são nesses momentos que os livros saem das estantes para se tornarem mais conhecidos e alcançarem as mãos dos leitores. No intuito de atender a essa necessidade, foi realizada a Estante Permanente de Destaque Dinâmico de Obras Literárias, descrita abaixo:

\footnotetext{
Foi criada na Biblioteca uma estante permanente de destaque dinâmico de obras literárias. "A estante permanente com obras literárias fica em local estratégico na entrada da biblioteca e com duas poltronas diferenciadas. Não houve um projeto instituído de forma detalhada, assim oficialmente não há como mensurar resultados, mas desde que foi implementada, por observação, percebe-se a exploração dos usuários da biblioteca deste tipo de material (B.9).
}

Outro fator relevante para o desenvolvimento de práticas de incentivo à leitura e citado pelos bibliotecários foi o perfil do profissional. Um dos respondentes acredita que "o perfil dos bibliotecários do IFSC, bem como a diversidade de público atendida por nossas bibliotecas seja um fator limitante a realização de ações de fomento à leitura na instituição" (B.1). Tratando do perfil profissional, outro bibliotecário complementa que "o bibliotecário precisa gostar, se interessar, ter a habilidade em cativar os usuários para a formação de 
leitores" (B.4). De acordo com este respondente, cada profissional possui habilidades que tem mais facilidade, "se ele tiver o interesse e gostar da atividade de formação de leitores, isso se torna algo natural a ser feito" (B.4). Entretanto, reflete que na realidade das bibliotecas do IFSC, "principalmente àquelas em que possui um ou dois bibliotecários por campus, possivelmente a formação de leitores será uma das últimas atividades na lista de prioridades que o bibliotecário tem de exercer no cotidiano" (B.4). Ou seja, na opinião deste respondente, o quantitativo de bibliotecários por campus afeta diretamente a realização de práticas de leitura e formação de leitores. Indo ao encontro deste pensamento, outro bibliotecário pontua, "penso que para esta formação [de leitores], de repente, devesse fazer um mapeamento das condições reais das bibliotecas e sua equipe disponível” (B.9). Nesta afirmação, o respondente não deixa explícito, mas, quando fala em "equipe disponível”, deduz-se que esteja se referindo tanto ao quantitativo quanto ao perfil dos bibliotecários para exercer tal atividade.

Com a análise preliminar dos dados coletados dos dez bibliotecários, foi possível ter uma ideia do perfil desses profissionais, entender o que pensam em relação à leitura e conhecer algumas práticas de incentivo à leitura desenvolvidas nas bibliotecas da instituição.

\section{Considerações finais}

O bibliotecário do IFSC é o profissional responsável por efetuar a gestão e administração da biblioteca do campus, atua em conjunto com os demais técnicos administrativos em educação. Por essa razão, torna-se imprescindível que o bibliotecário tenha voz para dissertar sobre uma temática tão importante que é a leitura.

Conceitualmente, estes bibliotecários compreendem a leitura como um ato de interpretação e produção de sentidos, pressupondo que a leitura tem uma estreita relação entre informação e conhecimento na clave da leitura de estudo e leitura de fruição. Relacionam a leitura com liberdade e compreensão de mundo e reconhecem a sua importância para a formação pessoal, acadêmica e profissional.

Do universo pesquisado, $90 \%$ trazem da infância o gosto pela leitura, o que pode ter contribuído para se constituírem em bibliotecários leitores. Os bibliotecários têm diferentes gostos literários. O contato com a literatura, além de favorecer o desenvolvimento humano do 
indivíduo, permite que se tenha a mente mais aberta para desenvolver as suas atividades inerentes à profissão.

Diante do perfil do bibliotecário, infere-se que o processo técnico de materiais bibliográficos toma a maior parte do trabalho destes profissionais. Outra informação obtida preliminarmente e que pode vir a ser confirmada em fase mais avançada da pesquisa é que o bibliotecário que atua nessas bibliotecas não tem o perfil para trabalhar com ações culturais e, consequentemente com a leitura.

No que tange às práticas de incentivo à leitura, estas podem ser divididas em atividades lúdicas sobre obras de literatura de ficção: roda de leitura, leitura e debates e sarau literário; e atividades de divulgação do livro e da leitura: exposição de livros, indicação de obras literárias, troca-troca de livros, estante expositiva e estante permanente de destaque de obras literárias. Trata-se de estratégias adotadas pelos bibliotecários desta instituição de ensino em oferecer ao seu público não só o livro de estudo, mas obras da literatura de lazer como potencial a escrita e a leitura.

Vale ressaltar que mais da metade das práticas descritas foram realizadas em bibliotecas de campi fora da região da Grande Florianópolis, na ocasião em que alguns bibliotecários foram lotados em campi do interior do estado.

O processo de formação de leitores não envolve apenas a leitura na infância, mas em toda a vida. O fomento à leitura precisa ser uma das ações de destaque nas bibliotecas, não uma atividade de segundo plano, realizada quando sobra tempo. E tanto o acervo da biblioteca quanto o bibliotecário são primordiais neste processo. Ainda que as bibliotecas do IFSC não sejam exclusivamente escolares, boa parte dos seus estudantes são adolescentes. É muito recorrente em nosso país que estudantes ingressem no ensino médio ou no ensino superior sem que tenham desenvolvido o hábito da leitura na infância. Independente da formação que o estudante teve durante o ensino fundamental, se agora ele está no IFSC, instituição reconhecida pelo ensino público, gratuito e de qualidade, então a responsabilidade é do IFSC. Se o estudante ainda não desenvolveu o gosto pela leitura, deve ser estimulado a partir de agora, e as bibliotecas têm um papel fundamental nesse processo.

As bibliotecas do IFSC atendem a um público muito diversificado, de diferentes níveis de ensino. Somado a isso, as contribuições desses bibliotecários para esta pesquisa nos levam a reflexões para se pensar novas formas de abordar o leitor, partindo da leitura de textos 
escritos para a leitura de mundo, e a partir daí procurar lidar com os estudantes/leitores sempre respeitando as subjetividades de cada um.

\section{Referências}

ALMEIDA JÚNIOR, Osvaldo Francisco de. Leitura, mediação e apropriação da informação. In: SANTOS, Jussara Pereira dos (Org.). A leitura como prática pedagógica na formação do profissional da informação. Rio de Janeiro: Fundação Biblioteca Nacional, 2007.

BARDIN, Laurence. Análise de conteúdo. 4. ed., rev. e atual. Lisboa: Ed. 70, 2009. 223 p.

BARRETO, Aldo de Albuquerque. A informação no processo do conhecimento: o texto e o hipertexto. DataGramaZero, v. 16, n. 3, 2015. Disponível em: http://hdl.handle.net/20.500.11959/brapci/8178. Acesso em: 02 nov. 2020.

CALDIN, Clarice Fortkamp. A função social da leitura da literatura infantil. Encontros Bibli: Revista Eletrônica de Biblioteconomia e Ciência da Informação, Florianópolis, v. 8, n. 15, p. 47-58, 2003. Disponível em: https://brapci.inf.br/index.php/res/download/52181. Acesso em: 25 out. 2020 .

FREIRE, Paulo. A importância do ato de ler: em três artigos que se completam. 45. ed. São Paulo: Cortez, 2003. 87 p.

LAKATOS, Eva Maria; MARCONI, Marina de Andrade. Fundamentos de metodologia científica. 7. ed. São Paulo: Atlas, 2010. 297 p.

MARTINS, Maria Helena. O que é leitura. 19. ed. São Paulo: Brasiliense, 2006. 93 p.

PETIT, Michèle. A arte de ler ou como resistir à adversidade. São Paulo: 34, 2010. 304 p.

PETIT, Michèle. Leituras: do espaço íntimo ao espaço público. São Paulo: 34, 2013. 168 p.

PETIT, Michèle. Leitura em regiões de conflito. Na Ponta do Lápis, São Paulo, v. 7, n. 16, p. 2-4, 2011. Disponível em: https://www.escrevendoofuturo.org.br/arquivos/4698/npl16.pdf. Acesso em: 02 out. 2020.

PETIT, Michèle. Os jovens e a leitura: uma nova perspectiva. São Paulo: 34, 2009. 192 p.

SILVA, Marta Benjamim da; BERNARDINO, Maria Cleide Rodrigues; NOGUEIRA, Carine Rodrigues. Políticas públicas para a leitura no Brasil: implicações sobre a leitura infantil.

Ponto de Acesso, Salvador, v. 6, n. 3, p. 20-46, abr. 2012. Disponível em: http://www.portalseer.ufba.br/index.php/revistaici/article/view/6437/4789. Acesso em: 6 nov. 2020.

SILVA, Vera Maria Tietzmann. Leitura literária \& outras leituras: impasses e alternativas no trabalho do professor. Belo Horizonte: RHJ, 2009. 216 p. 
SOUZA, Leila. A importância da leitura para a formação de uma sociedade consciente. In: ENCONTRO NACIONAL DE ENSINO E PESQUISA DA INFORMAÇÃO. Salvador, 2007. Anais eletrônicos... Salvador: UFBA, 2007. Disponível em:

http://www.cinform.ufba.br/7cinform/soac/papers/f42e0a81e967e9a4c538a2d0b653.pdf. Acesso em: 10 out. 2020. 